\title{
Durability characteristics of concrete using ferronickel slag fine aggregate and fly ash
}

\author{
Ashish Kumer Saha \\ PhD Student, Department of Civil Engineering, Curtin University, Perth, \\ WA, Australia (corresponding author: a.saha@postgrad.curtin.edu.au)
}

Prabir Kumar Sarker

Associate Professor, Department of Civil Engineering, Curtin University, Perth, WA, Australia

The production process of ferronickel generates an enormous amount of slag (FNS) as a by-product, which has potential for use as a fine aggregate in concrete. However, information regarding the durability of FNS aggregate concrete is very limited in the literature. This study evaluates the durability characteristics of concrete using FNS as up to $100 \%$ replacement of natural sand and fly ash as $30 \%$ replacement of cement. The volume of permeable voids (VPV) of concrete was found to increase with the increase of FNS aggregate. As a result, sorptivity and chloride permeability showed increasing trends with the increase of FNS aggregate. However, the pozzolanic reaction of fly ash reduced the porosity of the concrete, as evidenced by scanning electron microscopy and energy-dispersive X-ray spectroscopy. The specimens with FNS aggregate and fly ash were classified as 'excellent' in terms of VPV, 'low' in terms of chloride permeability and 'good' in terms of sorptivity. The use of fly ash also reduced the strength losses of FNS aggregate concrete subjected to alternate wet-dry cycles. Overall, a durability equivalent to that of conventional concrete could be achieved when FNS was used as a partial replacement of sand together with fly ash as a partial replacement of cement.

\section{Introduction}

Use of industrial by-products as supplementary cementitious material or aggregate can improve the sustainability of concrete production by conservation of natural resources and reduction of carbon dioxide $\left(\mathrm{CO}_{2}\right)$ emission. For this reason, the use of various by-products in concrete has been subject to increasing interest in recent times. Recycled concrete aggregate, steel slag, blast-furnace slag (BFS), coal bottom ash (CBA) and foundry slag are some common by-products used as replacement for natural aggregates. It is important to understand the effect of a by-product material on the durability of concrete in order to use it in the construction of structures. This paper presents a study on the durability-related properties of concrete using ferronickel slag (FNS) in place of natural sand and fly ash as a partial replacement for cement.

Nickel smelters generate a substantial amount of molten slag as a by-product because the usual ores contain very low-grade nickel. About $12-14 \mathrm{t}$ of FNS is produced as a by-product in the manufacturing process of $1 \mathrm{t}$ of ferronickel (Saha and Sarker, 2017a). The molten FNS can be either solidified by air at a slow rate of cooling or granulated by water at a rapid rate of cooling. The physical properties of granulated FNS make it a potential candidate for use as a fine aggregate in concrete (Katsiotis et al., 2015; Saha and Sarker, 2017b). The use of FNS is considered to be safe because the quantities of heavy metals in leachates are much lower than the allowable limits. Concrete using FNS as a partial replacement for sand has exhibited improved mechanical properties, such as compressive strength, tensile strength and modulus of elasticity, as compared to those of the control specimens (Sakoi et al., 2013). However, full replacement of sand by FNS has reduced strength due to poor gradation of the aggregate (Shoya et al., 1999).
Few studies are available in the literature on drying shrinkage, freeze-thaw resistance, carbonation, permeability and the alkali-silica reaction (ASR) of FNS aggregate concrete. Sato et al. (2011) reported reduced freeze-thaw resistance of concrete due to bleeding caused by FNS aggregates. Similarly, Togawa et al. (1996) reported a reduced durability factor in freezing and thawing cycles with the use of air- or water-cooled FNS aggregates. The authors suggested that the use of supplementary cementing materials such as BFS, silica fume and limestone powder could improve the freeze-thaw resistance of concrete. Sakoi et al. (2013) reported that the freeze-thaw resistance of FNS aggregate concrete was identical to that of natural aggregate concrete. Tomosawa et al. (1997) pointed out the potential ASR expansion of FNS aggregate. However, they demonstrated that the use of low-alkali cement and supplementary cementing material such as fly ash and BFS could reduce the ASR expansion. Apparently, not every type of FNS aggregate is alkali-silica reactive. Rapidly cooled slag may contain amorphous silica that could cause ASR expansion. However, slowly cooled FNS contains crystalline silica, which is more stable and does not exhibit expansion due to ASR (Choi and Choi, 2015). It has been observed in the authors' ongoing study that the use of a class F fly ash could successfully mitigate the potential ASR expansion of FNS aggregates (Saha and Sarker, 2016). However, FNS aggregates did not have any notable impact on the drying shrinkage, carbonation and permeability properties of concrete (Sakoi et al., 2013; Shoya et al., 1999).

It was found that some important durability-related properties such as porosity, sorptivity, chloride permeability and resistance to wet-dry cycles of FNS aggregate concrete had not been studied in the past. Resistance against wet-dry cycles is 
an important aspect of the durability of concrete. Previous studies have shown that electric arc furnace (EAF) slag concrete exhibits a strength loss of about $30 \%$ due to exposure to alternate wet-dry cycles (Manso et al., 2006; Pellegrino and Gaddo, 2009). Other studies (Andrade et al., 2009; Kadam and Patil, 2015; Yüksel et al., 2007) have shown that concrete containing manufactured aggregates, such as CBA and BFS, exhibit higher sorptivity as compared to the natural aggregate concrete. However, the use of fly ash as a supplementary cementing material was shown to reduce the sorptivity of concrete by pozzolanic reaction (Dragaš et al., 2016; Soutsos et al., 2017). Chloride permeability of concrete was also affected by the use of manufactured aggregate. The use of high-volume CBA was shown to increase the chloride permeability of concrete (Ghafoori and Bucholc, 1996; Kou and Poon, 2009). Supplementary cementing material such as fly ash was also shown to improve the chloride permeability of concrete (Silva et al., 2017). These studies have shown that it is important to evaluate the durability characteristics of concrete when an industrial by-product is considered for use as a replacement for natural aggregate. Therefore, this paper focuses on the durability-related properties of FNS aggregate concrete.

\section{Research significance}

This study evaluates the durability properties of concrete containing FNS aggregates. The FNS used was a by-product of the smelting of garnierite nickel ore found in New Caledonia. The smelter produces about 1.7 million tonnes of FNS annually (Rahman et al., 2017), which is granulated using seawater cooling. The slag has been used by the local construction industries as a landfill material as well as a replacement for natural sand in concrete. Despite its broad application, about 25 million tonnes of slag has been accumulated in the premises of the plant. This paper presents the volume of permeable voids (VPV), sorptivity, chloride permeability and the resistance against wet-dry cycles of concrete containing FNS aggregate with or without fly ash as a partial cement replacement. Investigations of porosity and microstructures were conducted by scanning electron microscopy (SEM) and energy-dispersive X-ray spectroscopy (EDS) in order to gain an insight into the effects of FNS and fly ash on the properties of concrete.

\section{Experimental work}

Materials

Commercially available Portland cement (PC) was used as a primary binder and class $\mathrm{F}$ fly ash was used as a supplementary cementing material. Natural silica sand and FNS were used as fine aggregates and crushed granite with a maximum size of $20 \mathrm{~mm}$ was used as coarse aggregate. Table 1 presents the chemical compositions of the binders and the FNS aggregate. It can be seen that the FNS was mainly composed of silicon, magnesium and iron. The main components of
Table 1. Chemical compositions and loss on ignition (LOI) of PC FNS and fly ash (mass \%)

\begin{tabular}{|c|c|c|c|}
\hline Material & PC & Fly ash & FNS \\
\hline Silicon dioxide $\left(\mathrm{SiO}_{2}\right)$ & $20 \cdot 29$ & $76 \cdot 34$ & $53 \cdot 29$ \\
\hline Aluminium oxide $\left(\mathrm{Al}_{2} \mathrm{O}_{3}\right)$ & 5.48 & $14 \cdot 72$ & $2 \cdot 67$ \\
\hline Iron oxide $\left(\mathrm{Fe}_{2} \mathrm{O}_{3}\right)$ & $2 \cdot 85$ & 3.69 & 11.9 \\
\hline Magnesium oxide (MgO) & $1 \cdot 24$ & 0.54 & $31 \cdot 6$ \\
\hline Sulfur trioxide $\left(\mathrm{SO}_{3}\right)$ & $2 \cdot 49$ & $0 \cdot 11$ & - \\
\hline Calcium oxide $(\mathrm{CaO})$ & $63 \cdot 11$ & 0.60 & 0.42 \\
\hline Sodium oxide $\left(\mathrm{Na}_{2} \mathrm{O}\right)$ & 0.29 & $0 \cdot 19$ & 0.11 \\
\hline Potassium oxide $\left(\mathrm{K}_{2} \mathrm{O}\right)$ & 0.45 & 0.96 & - \\
\hline Chromium oxide $\left(\mathrm{Cr}_{2} \mathrm{O}_{3}\right)$ & 0.02 & - & 1.08 \\
\hline Phosphorus pentoxide $\left(\mathrm{P}_{2} \mathrm{O}_{5}\right)$ & $0 \cdot 17$ & $0 \cdot 10$ & - \\
\hline Strontium oxide (SrO) & 0.05 & - & - \\
\hline Titanium dioxide $\left(\mathrm{TiO}_{2}\right)$ & $0 \cdot 27$ & 0.61 & - \\
\hline Manganese oxide $\left(\mathrm{Mn}_{2} \mathrm{O}_{3}\right)$ & 0.08 & 0.07 & - \\
\hline Zinc oxide $(\mathrm{ZnO})$ & 0.04 & - & - \\
\hline Nickel oxide (NiO) & - & - & $0 \cdot 1$ \\
\hline Cobalt oxide $\left(\mathrm{CO}_{3} \mathrm{O}_{4}\right)$ & - & - & 0.01 \\
\hline LOI & $3 \cdot 39$ & 0.53 & - \\
\hline
\end{tabular}

the fly ash were silica and alumina; the calcium content was very low.

The physical appearance of the natural sand and the FNS aggregate is shown in Figure 1. It can be seen that FNS consisted of angular particles of varying sizes, as compared to the round, sand particles of relatively smaller sizes. The FNS aggregate consisted of larger particles with a porous structure. The physical properties of the sand, FNS and coarse aggregates are given in Table 2. It is noticeable that the FNS aggregates have a higher density and water absorption as compared to natural sand. The properties of FNS aggregate are within the allowable limits recommended by the Australian standard AS 2758.1 (SA, 1998).

The particle size distributions of fine aggregates such as FNS, natural sand and their combination taking 50\% from each type are presented in Figure 2. The allowable limits of fine aggregate gradation recommended by the Australian standard AS 2758.1 (SA, 1998) are also plotted in the figure. It can be seen that FNS aggregate consisted of more large particles when compared to sand. The grading curve for FNS exceeds the lower limit of the Australian standard due to the presence of fewer fine particles. However, the combination of $50 \%$ FNS and $50 \%$ natural sand provides a well-graded fine aggregate. The flow test was conducted for the sand, FNS and their combination using a sand flow cone. The results are given in Table 3. It can be seen that the flow time for $100 \%$ natural sand was $17 \cdot 20 \mathrm{~s}$, which was increased to $26 \cdot 20 \mathrm{~s}$ by the inclusion of $50 \%$ FNS in the fine aggregate. In contrast, the $100 \%$ FNS fine aggregate did not flow at all. The angular shape, larger size and rough surface of the FNS particles as compared to smaller, round and smooth sand particles reduced the flow time of the fine aggregate, eventually reaching no flow for $100 \% \mathrm{FNS}$. 


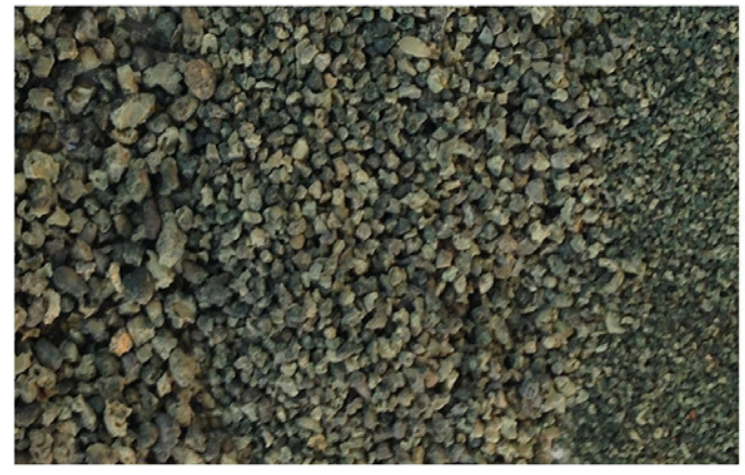

(a)

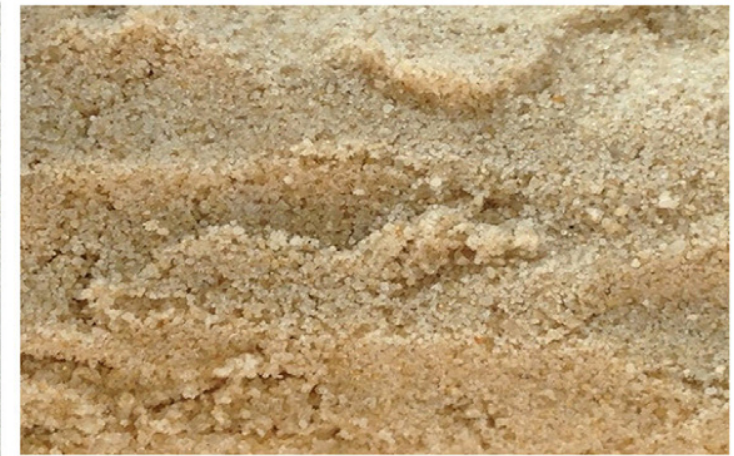

(b)

Figure 1. (a) FNS aggregate and (b) natural sand

Table 2. Physical properties of aggregates

\begin{tabular}{|lccc|} 
Property & $\begin{array}{c}\text { Coarse } \\
\text { aggregate }\end{array}$ & Sand & FNS \\
\hline Saturated surface dry (SSD) density: $\mathrm{t} / \mathrm{m}^{3}$ & 2.71 & $2 \cdot 16$ & 2.78 \\
Apparent particle density: $\mathrm{tm}^{3}$ & 2.73 & 2.32 & 2.85 \\
Fineness modulus & 7.6 & 1.95 & 4.07 \\
Water absorption & 0.48 & 0.35 & 0.42 \\
\hline
\end{tabular}

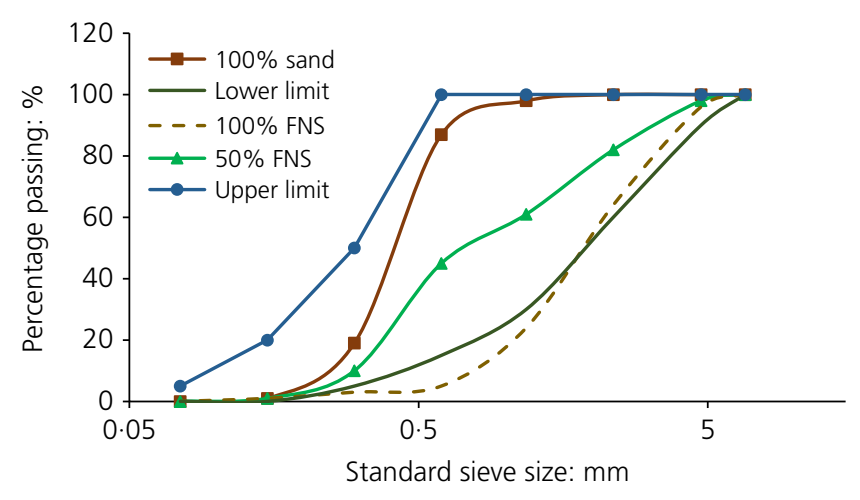

Figure 2. Particle size distribution of sand, FNS and their combination

Table 3. Flow time of the fine aggregates

\begin{tabular}{|ll|}
\hline Sample specification & Time to flow: $\mathbf{s}$ \\
\hline $100 \%$ sand & $17 \cdot 2$ \\
\hline $50 \%$ FNS and $50 \%$ sand & $26 \cdot 2$ \\
\hline $100 \%$ FNS & Did not flow \\
\hline
\end{tabular}

\section{Mixture proportions and test methods}

The concrete mix design was conducted by the absolute volume method and the mixture proportions are shown in Table 4 . FNS fine aggregate was used as 50\% and $100 \%$ volume replacement for natural sand. FNS replacement of $50 \%$ in the concrete mixture was selected because this proportion resulted in the maximum compressive strength with good flowability of the mortar mixture (Saha and Sarker, 2017b). The water-to-binder ratio was kept constant at 0.33 for all of the mixtures. The aggregates were prepared to saturated surface dry condition before mixing of the concrete. A naphthalene-based superplasticiser was used to improve the workability of the mixtures. For one group of mixes, $100 \%$ PC was used as the binder and for the other group, $30 \%$ fly ash was used as a cement replacement. Fly ash (Saha and Sarker, 2016) was adopted as a supplementary cementing material owing to its favourable ASR mitigation mechanism. The mixes are designated as PC-FNS and FA-FNS for without fly ash and with $30 \%$ fly ash, respectively. The number at the end of mix identification code represents the percentage of sand replacement by FNS. A standard slump test was carried out in order to determine the workability of the fresh concrete mixtures. The concrete was then placed into $100 \mathrm{~mm} \times 200 \mathrm{~mm}$ cylindrical moulds and compacted using a vibrating table. The test specimens were demoulded $24 \mathrm{~h}$ after casting and then cured in limewater at $23^{\circ} \mathrm{C}$ for $28 \mathrm{~d}$. The mean values of the reported results were obtained from the test results of three identical specimens.

Cylinder compressive strengths were determined in accordance with the Australian standard AS 1012.9 (SA, 2014). The porosity of concrete specimens was determined by the VPV test in accordance with the standard ASTM C642 (ASTM, 2006). The test measures the porosity of concrete by absorption of water. Discs that were $50 \mathrm{~mm}$ thick were cut from the concrete cylinders after curing for $28 \mathrm{~d}$. The mass of the test sample was recorded after oven drying at $110^{\circ} \mathrm{C}$ for a period of $24 \mathrm{~h}$. The saturated surface dry weight was then recorded after immersion of the sample in water for $48 \mathrm{~h}$. Finally, the samples were boiled in water for $5 \mathrm{~h}$ and weighed after cooling down to room temperature. The volume of the permeable voids was calculated from this recorded weight.

The sorptivity test was conducted to evaluate the capillary suction of concrete as per ASTM C1585 (ASTM, 2004). After the $28 \mathrm{~d}$ of the curing period, the concrete cylinders were cut into $50 \mathrm{~mm}$ thick discs. The samples were oven dried to achieve a constant weight before beginning the sorption by 
Table 4. Concrete mix proportions

\begin{tabular}{|c|c|c|c|c|c|c|c|}
\hline \multirow[b]{2}{*}{ Mix ID } & \multicolumn{2}{|c|}{ Binder: $\mathrm{kg} / \mathrm{m}^{3}$} & \multicolumn{2}{|c|}{ Fine aggregate: $\mathrm{kg} / \mathrm{m}^{3}$} & \multirow{2}{*}{$\begin{array}{l}\text { Water: } \\
\mathrm{kg} / \mathrm{m}^{3}\end{array}$} & \multirow{2}{*}{$\begin{array}{c}\text { Coarse } \\
\text { aggregate: } \mathrm{kg} / \mathrm{m}^{3}\end{array}$} & \multirow{2}{*}{$\begin{array}{c}\text { Superplasticiser: } \\
\mathrm{kg} / \mathrm{m}^{3}\end{array}$} \\
\hline & Cement & Fly ash & Sand & FNS & & & \\
\hline PC-FNSO & 390 & 0 & 710 & 0 & 129 & 1194 & 4 \\
\hline PC-FNS50 & 390 & 0 & 355 & 435 & 129 & 1194 & 4 \\
\hline PC-FNS100 & 390 & 0 & 0 & 870 & 129 & 1194 & 4 \\
\hline FA-FNSO & 273 & 117 & 710 & 0 & 129 & 1194 & 4 \\
\hline FA-FNS50 & 273 & 117 & 355 & 435 & 129 & 1194 & 4 \\
\hline FA-FNS100 & 273 & 117 & 0 & 870 & 129 & 1194 & 4 \\
\hline
\end{tabular}

keeping only the bottom surface in contact with water. The sides of the specimen were sealed by duct tape and the top surface by a plastic sheet. As a result, water movement was allowed only from the bottom surface. The mass increments were measured for a period of $9 \mathrm{~d}$, with the designated time intervals as suggested in the standard. The sorptivity coefficient was measured from the slope of the plot of absorption against the square root of time.

The rapid chloride permeability test (RCPT) was conducted in accordance with ASTM C1202 (ASTM, 1997). Although the RCPT may give high variability of results and may not be considered as a direct measure of durability, it is used as an indication of chloride ingress into concrete. Concrete cylinders were cut to $50 \mathrm{~mm}$ thick discs after $28 \mathrm{~d}$ of curing and kept in a vacuum desiccator for $3 \mathrm{~h}$ at a pressure of $50 \mathrm{~mm} \mathrm{Hg}$, followed by $18 \mathrm{~h}$ of immersion in water. The saturated samples were then subjected to a direct current of $60 \mathrm{~V}$ for a duration of $6 \mathrm{~h}$, keeping one side of the specimen in contact with $3 \%$ sodium chloride $(\mathrm{NaCl})$ solution and the other side in contact with $0.3 \mathrm{M}$ sodium hydroxide $(\mathrm{NaOH})$ solution. During the test period, the total charge passing through the specimens in coulombs was recorded.

In order to evaluate the resistance of concrete to wet-dry cycles, the samples were exposed to cycles of alternate immersion in water and drying at a temperature of $110^{\circ} \mathrm{C}$. This exposure condition was considered in order to evaluate the effects of adverse environmental conditions on concrete with age. The exposure to wet-dry cycles started after initial curing of the samples for $28 \mathrm{~d}$. The samples were kept in an oven at $110^{\circ} \mathrm{C}$ for $8 \mathrm{~h}$, after which they were immersed in water at $23^{\circ} \mathrm{C}$ for $15 \mathrm{~h}$ to complete one cycle of drying and wetting. After 28 cycles of alternate wetting and drying, the changes in compressive strength and mass of the specimens were measured. In order to understand the effect of wet-dry cycles, microstructural observations were conducted using SEM and EDS.

\section{Results and discussion}

\section{Workability and compressive strength}

The workability of the freshly mixed concrete was determined by a slump test. The slump values were $120 \mathrm{~mm}, 140 \mathrm{~mm}$ and
$110 \mathrm{~mm}$ for the PC-only (PC-FNS) mixtures for 0,50 and $100 \%$ FNS, respectively. The slump values of the mixtures with $30 \%$ fly ash were $130 \mathrm{~mm}, 155 \mathrm{~mm}$ and $125 \mathrm{~mm}$ for 0,50 and $100 \%$ FNS content, respectively. Although all of the mixtures had good workability, it can be seen that slump increased with the use of fly ash and $50 \%$ FNS fine aggregate. This is attributed to the well-known ball-bearing effect of fly ash particles and relatively large particles of FNS aggregate as compared to sand. The use of $50 \%$ FNS reduced the total surface area of the fine aggregate and thus there was more paste available to increase the workability. However, workability then decreased with the use of $100 \%$ FNS aggregate because all the fine aggregate particles were angular, which increased the friction against movements among the particles.

The mean density of the hardened concretes of all the mixtures was $2486 \mathrm{~kg} / \mathrm{m}^{3}$ with a coefficient of variation of $1.05 \%$. The compressive strength results are given in Figure 3 . It can be seen that the compressive strengths of the PC-FNS mixes were 61, 66 and $44 \mathrm{MPa}$ for 0,50 and $100 \%$ FNS, respectively. Thus, it can be seen that compressive strength increased by $8 \%$ for $50 \%$ sand replacement by FNS aggregates and then decreased by $26 \%$ for $100 \%$ replacement of sand by FNS. This is because $50 \%$ FNS produced a well-graded aggregate and $100 \%$ FNS produced a relatively poorly graded aggregate, as shown in Figure 2. Besides, there was a gradual reduction of compressive strength due to the use of $30 \%$ fly ash as a cement

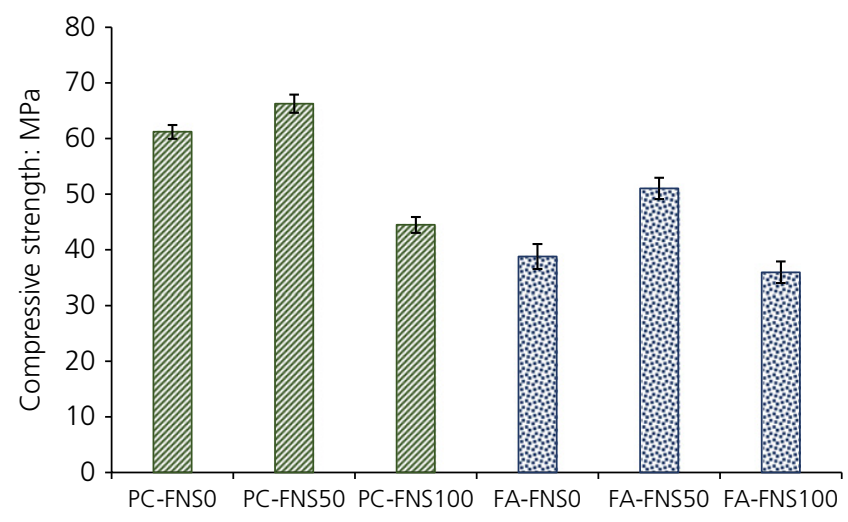

Figure 3. Compressive strength after $28 \mathrm{~d}$ of curing 
replacement. The compressive strengths of the mixtures with $30 \%$ fly ash were 39,51 and $36 \mathrm{MPa}$ for 0,50 and $100 \% \mathrm{FNS}$, respectively. Although compressive strength is reduced by fly ash, it is considered necessary to use fly ash as an ASR mitigating measure for the FNS aggregate.

\section{Volume of permeable voids}

The VPV (Vicroads, 2007) test is used to determine the total porosity of concrete that consists of capillary pores, gel pores, air voids and microcracks. Thus, the VPV indicates the ease of penetration of fluids into concrete from the surroundings. The changes of VPV of concrete with the percentage of FNS content are plotted in Figure 4. It can be seen that the porosity of the samples gradually increased with the increase of FNS aggregate for both of the binder groups, with and without fly ash. The VPV values of the concrete specimens without fly ash in the binder were $5 \cdot 79,7 \cdot 80$ and $11.23 \%$ for 0,50 and $100 \%$ FNS content, respectively. The increase of porosity is attributed to the increase of voids in concrete due to the larger size and angular shape of the FNS particles. The durability classifications according to the VPV value of concrete by VicRoads (2007) are also shown in Figure 4. As shown in the figure, concretes with a VPV value below $11 \%$ are classified as 'excellent' and those between 11 and $13 \%$ are classified as 'good'. Thus, the mixtures containing 0 and $50 \%$ FNS are classified as 'excellent' whereas the mixture containing 100\% FNS is marginally classified as 'good' concrete in terms of the VPV.

It can be seen from Figure 4 that the VPV of concrete generally reduced by the use of fly ash as a cement replacement for both types of aggregate. The trend of the change of VPV with the increase of FNS aggregate was similar for the concretes with or without fly ash. The VPV values were 5·23, 7·18 and $9 \cdot 76 \%$ for 0,50 and $100 \%$ FNS content, respectively, in the concrete containing $30 \%$ fly ash as cement replacement. The reduction of porosity by the inclusion of fly ash is

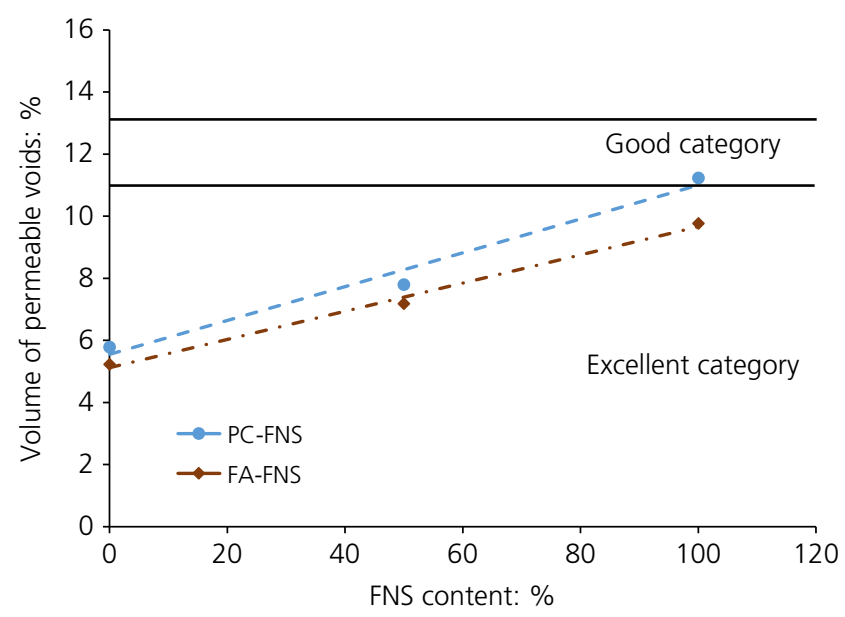

Figure 4. Variation of the VPV with FNS content in concrete attributed to its higher fineness than cement and its pozzolanic reaction. The reduction of permeability by the addition of fly ash (Bijen, 1996; Shehata et al., 1999) has been well documented in previous studies. As shown in Figure 4, the concrete specimens containing $30 \%$ fly ash and up to $100 \%$ FNS are classified as 'excellent' according to the VPV values.

\section{Sorptivity coefficient}

The sorptivity coefficients of the samples of both binder groups are plotted in Figure 5. The sorptivity coefficients of the concrete specimens without fly ash were $0 \cdot 085,0 \cdot 153$ and $0.219 \mathrm{~mm} / \mathrm{min}^{1 / 2}$ for 0,50 and $100 \%$ FNS, respectively. It is noticeable that the sorptivity value of concrete with $100 \%$ FNS aggregate exceeded the allowable limit of $0.21 \mathrm{~mm} / \mathrm{min}^{1 / 2}$ suggested by Cement Concrete \& Aggregates Australia (CCAA, 2009). The higher sorptivity coefficient was due to the higher internal voids associated with the addition of FNS aggregates. The larger size and higher angularity of the FNS particles increased the internal voids, which eventually increased the absorption of concrete. The relatively larger size and angular shape of the FNS particles can be seen in the grading curve (Figure 2) and in Figure 1(a), respectively.

The sorptivity coefficients of the specimens using 30\% fly ash were $0.061,0.092$ and $0.123 \mathrm{~mm} / \mathrm{min}^{1 / 2}$ for 0,50 and $100 \%$ FNS, respectively. Thus, sorptivity was significantly reduced by the use of fly ash. The sorptivity values of the specimens of this group are well below the allowable limit of $0.21 \mathrm{~mm} / \mathrm{min}^{1 / 2}$ suggested by CCAA. There are two primary reasons contributing to the reduction of sorptivity of the fly ash concrete. First, fly ash contains a high volume of amorphous silica (Saha and Sarker, 2016), which reduced the capillary pores by the products of pozzolanic reaction with portlandite. Second, fly ash particles are generally finer than cement particles (Kuroda et al., 2000), and reduced the interconnecting voids by acting as nucleation sites and their pore filling effect.

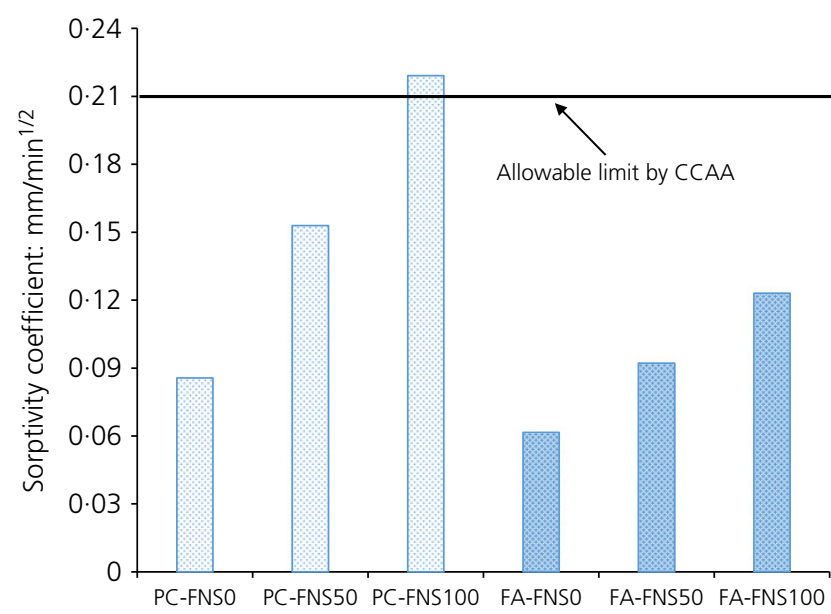

Figure 5. Variation of sorptivity with FNS content 


\section{Chloride permeability}

Chloride permeability of the concrete samples was determined by RCPT. The test is based on the principle that the total charge passing through a concrete sample is an indicator of the chloride ion penetration. This test is relatively quick and gives reliable data to compare the chloride permeability values for different specimens. The total charge passed through the concrete samples of two binder groups is presented in Figure 6. The ASTM C1202 (ASTM, 1997) classifications of concrete from 'very low' to 'high' values of charge passed are also shown in this figure. It can be seen that the charge passed through the samples with no fly ash (PC-FNS) was within a range of 2066-3335 C. The value of charge increased gradually with the increase of the percentage of FNS aggregate. The chloride permeability of the specimens of PC-FNS series has been classified as 'moderate level' by the ASTM C1202 (ASTM, 1997) standard. The FNS aggregates increased the permeable voids in concrete, as discussed in the previous two sections, which is the primary reason for the increase of chloride permeability with the increase of FNS aggregates.

In contrast, the concrete specimens with $30 \%$ fly ash in the binder exhibited lower chloride penetration for all the three fine aggregates. The charges passed through the samples were 698,1030 and $1074 \mathrm{C}$ for 0,50 and $100 \%$ FNS, respectively. Thus, the specimens are classified as 'very low' chloride permeability for $100 \%$ natural sand and 'low' for using 50 and $100 \%$ FNS aggregate. It was shown that fly ash reduced the pore size (Kuroda et al., 2000) by reducing the thickness of the interfacial transition zone between the binder matrix and the aggregates. Furthermore, fly ash also reduces the hydroxyl ion (Shehata et al., 1999) in the pore solution of concrete, thus reducing the charge passed through the concrete. Overall, while the use of FNS aggregate increased the pore volume, fly ash helped to reduce the porosity and the alkalinity of the pore solution to reduce the chloride permeability of the concrete.

\section{Effect of wet-dry cycles}

\section{Strength and mass variations due to wet-dry cycles}

The concrete samples were exposed to alternate wetting and drying for 28 cycles and each cycle consisted of $8 \mathrm{~h}$ of oven drying at $110^{\circ} \mathrm{C}$ followed by $15 \mathrm{~h}$ of immersion in water at room temperature. The samples were visually observed before and after the wet-dry exposures. The specimens of mixture PC-FNS100 are shown in Figure 7 as the typical appearance of the specimens after the wet-dry cycles. No visible crack or damage was observed in the specimens after 28 cycles of the wet-dry conditions. However, there was a thin layer of whitish substance over the surface of the samples. This surface deposition is attributed to slow migration of the hydrated product from inside the concrete by the alternate wetting and drying conditions.

The compressive strengths of the specimens after the cycles of wet-dry exposures are presented in Figure 8. The figure also shows the compressive strength of corresponding mixtures at $58 \mathrm{~d}$ of age without exposure to wet-dry cycles. The strength reduction of the specimens is considered to be due to the minor internal damage at the microstructural level by the alternate expansions and contractions because of the alternate changes of temperature between $110^{\circ} \mathrm{C}$ and $23^{\circ} \mathrm{C}$. In addition, the moisture movement and drying shrinkage due to the variation of humidity condition are also considered to play a role in the strength reduction of concrete.

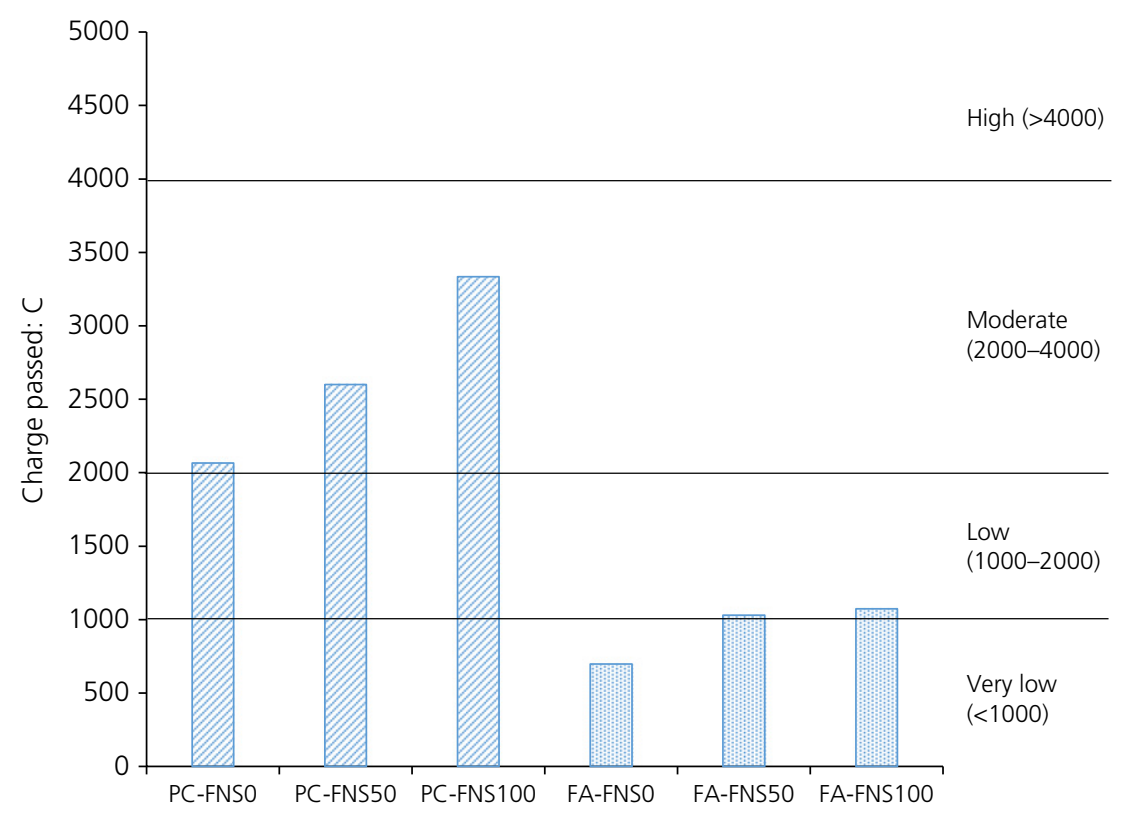

Figure 6. Charge passed during rapid chloride permeability test 

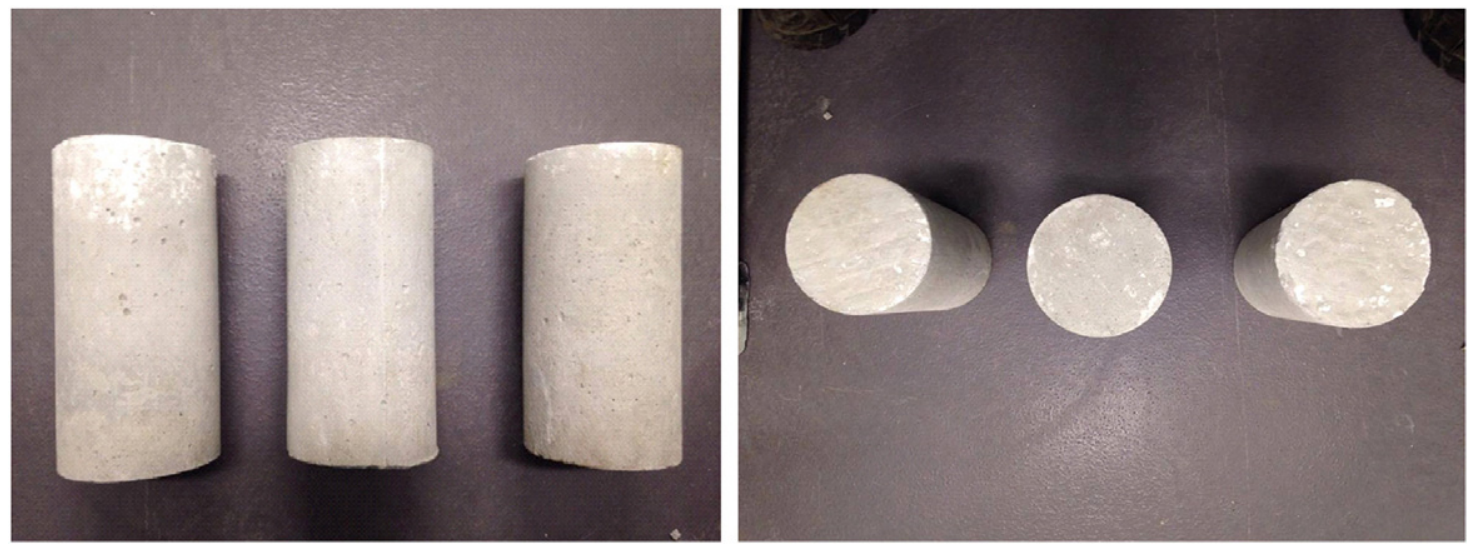

Figure 7. Physical appearance of PC-FNS100 samples after wet-dry cycles

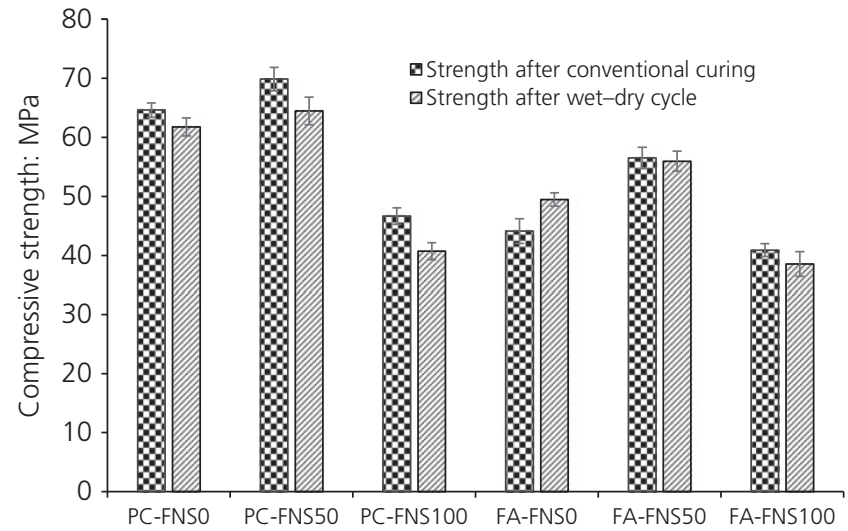

Figure 8. Comparison of compressive strength following exposure to wet-dry cycles

The percentages of changes in compressive strength after the wet-dry cycles are presented in Figure 9. It is noticeable that the specimens without fly ash (PC-FNS0) exhibited a strength loss of $4.42 \%$ after the exposures to wet-dry cycles. The strength loss gradually increased for the PC-FNS specimens with the increment of FNS content in concrete. The strength loss was $7 \cdot 73$ and $12 \cdot 71 \%$ for 50 and $100 \%$ FNS content, respectively. Manso et al. (2006) and Pellegrino and Gaddo (2009) used similar wet-dry conditions for concrete using steel slag aggregates and reported a strength loss of about 30\%. Therefore, FNS aggregate used in this study showed comparatively lower strength loss than the steel slag aggregate concrete. The use of FNS aggregates increased the permeability and absorption of concrete, as shown in Figures 3-5. Thus, it is possible to have higher water penetration during the wetting cycles, which may result in an increased vapour pressure in the specimens containing FNS aggregate during the drying cycle. Therefore, there are three principal reasons for the strength reduction of concrete caused by the internal damage due to wet-dry cycles: $(a)$ the simultaneous wetting and drying at elevated temperature causing sudden thermal expansion and

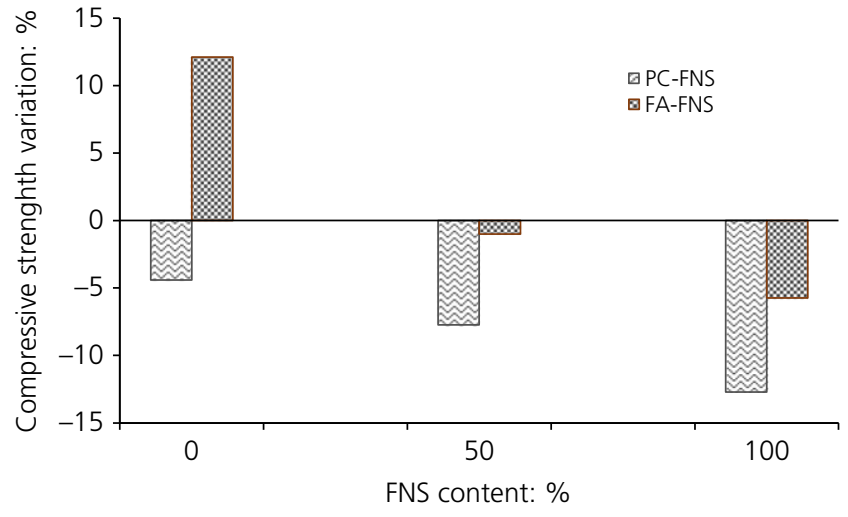

Figure 9. Percentage of strength change by the wet-dry cycles

contraction; (b) water vapour pressure during the drying cycle; and $(c)$ the leaching out of some hydrated product. The combined effect of these aspects is considered to cause strength losses of the specimens.

As shown in Figure 8, the concrete specimens with 30\% fly ash as cement replacement showed relatively lower strength loss after the wet-dry cycles. The compressive strength of samples containing $100 \%$ natural sand and $30 \%$ fly ash increased by $12 \%$ after the wet-dry cycles. There were 1 and $6 \%$ strength losses in the samples with 50 and $100 \%$ FNS aggregate, respectively. The increment of compressive strength is attributed to the pozzolanic reaction of fly ash. The alternate wetting and drying cycles at elevated temperature accelerated the pozzolanic reaction of fly ash, which caused the smaller strength loss for the concrete containing FNS aggregate. Furthermore, the effect of water vapour depends on the porosity and water absorption of the samples. The inclusion of fly ash increases the density of the paste matrix and reduces the concrete porosity and absorption, which has been discussed in earlier sections. As a result, the compressive strength of the samples with $30 \%$ fly ash and 50\% FNS aggregate suffered only marginal strength loss (1\%), 
whereas samples with $100 \%$ PC as the binder and 50\% FNS aggregate suffered a strength loss about $8 \%$.

The mass losses of the concrete specimens due to wet-dry cycles are presented in Figure 10. It can be seen that weight loss increased with the increase of FNS content for both of the binder types. The weight loss was within a range of $0 \cdot 45-1 \cdot 89 \%$. The weight loss was almost doubled for a particular binder group due to the inclusion of $100 \%$ FNS aggregate as compared to that with $100 \%$ natural sand. The trend of the mass loss is similar to the strength loss for both the binder groups. The reasons for mass changes by the wet-dry cycles are considered to be the same as those for the strength changes, as discussed above.

\section{Microstructural observation after wet-dry cycles}

The SEM images and EDS of the concrete microstructures after the wet-dry cycles are used to understand the effects of FNS and fly ash. The SEM image of the specimen containing 100\% natural sand and no fly ash (PC-FNS0) is presented in Figure 11(a). It can be seen that there was development of internal cracks due to the aggressive wet-dry cycle exposure. The EDS of the reaction product is presented in spectrum 1 . It can be seen that the hydrated product had a high intensity of calcium (Ca) and low intensity of silicon ( $\mathrm{Si}$ ). This is because the binder did not undergo any pozzolanic reaction, as there was no fly ash in this specimen. The SEM image of the specimen with 100\% $\mathrm{PC}$ as the binder and $100 \%$ FNS aggregate (PC-FNS100) is presented in Figure 11(b). The presence of cracks can be seen at the interface of aggregate and binder in this microstructure. The corresponding EDS (spectrum 2) shows a calcium-rich phase that is similar to the EDS (spectrum 1) of specimen PC-FNS0.

The SEM image of the specimen with $30 \%$ fly ash and no FNS is presented in Figure 11(c). It can be seen that the hydrated

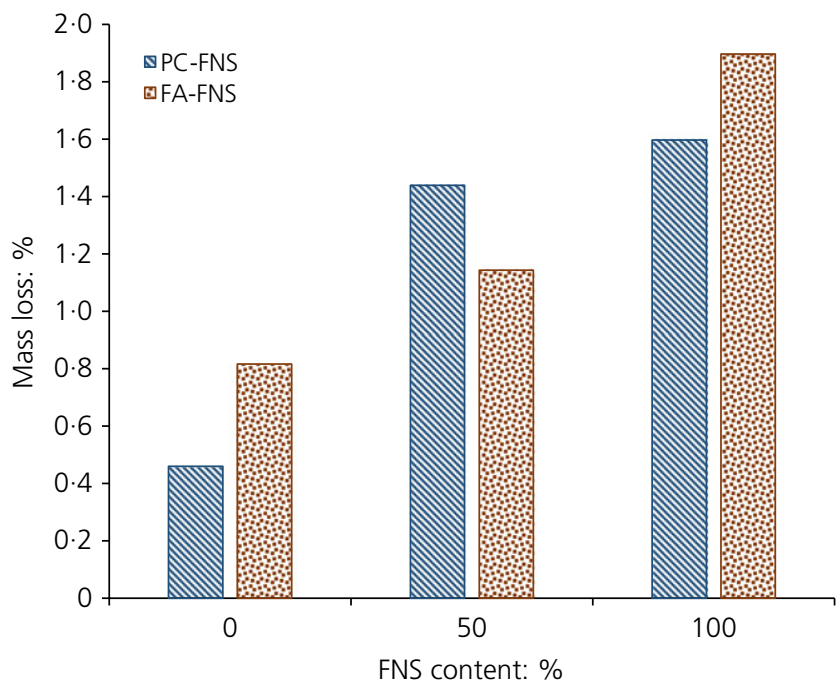

Figure 10. Mass loss attributable to exposure to wet-dry cycles product consisted of a dense structure, some fly ash particles underwent the pozzolanic reaction and some others were initiating the process. Additionally, the fine line of a crack can be seen in the image, which is significantly thinner as compared to those observed in the SEM image of specimen PC-FNS0. The EDS data in spectrum 3 confirm the pozzolanic reaction of fly ash, showing a product of higher intensity of silica and low intensity of calcium. Thus, the wet-dry cycle accelerated the pozzolanic reaction of the amorphous silica of fly ash producing a silica-rich hydrated product, commonly known as calciumsilicate-hydrate gel. Figure 11(d) presents the microstructure of the specimen with 30\% fly ash and 100\% FNS aggregate. The contribution of the pozzolanic reaction product of fly ash to fill up the pores can be seen in this image. This contributed to increase the density of the binder matrix and improve the bond between the aggregate and binder. Thus, the use of fly ash helped to reduce the strength loss of FNS aggregate concrete after the wet-dry cycles, as shown in Figure 9.

\section{Conclusions}

By-product FNS was used as fine aggregate to replace 50 and $100 \%$ natural sand, and a class F fly ash was used as 30\% replacement of cement in concrete. The durability characteristics of the concrete specimens were studied by evaluating the VPV, sorptivity, chloride permeability and resistance to exposure to wet-dry cycles. Generally, VPV was found to increase with the increase of FNS aggregates replacing natural sand. Chloride permeability and capillary absorption of concrete were also found to increase with the increase of sand replacement by FNS aggregate. These increases are attributed to the increase of porosity by the relatively large size and angular shape of the FNS particles. The increase of FNS content also showed higher strength and mass losses due to the exposure to alternate wetdry cycles. However, the pozzolanic reaction of fly ash reduced the permeable voids, as evidenced by the SEM images and EDS data. Thus, the chloride permeability and capillary water absorption were also reduced by fly ash. The concrete samples with fly ash also suffered from lower strength reduction after the wet-dry cycles as compared to the samples without fly ash. The compressive strength of the sample with 50\% FNS and 30\% fly ash remained almost unchanged after exposure to the wet-dry cycles. The sorptivity coefficient of this mix was well below the recommended value of $0.21 \mathrm{~mm} / \mathrm{min}^{1 / 2}$ and the rapid chloride permeability was classified as low. Consequently, the durability performance of the concrete containing 50\% FNS fine aggregate and $30 \%$ fly ash is considered equivalent to that of the concrete using 100\% natural sand and 100\% cement. Therefore, combined use of FNS fine aggregate and fly ash is a promising option for environmentally friendly and durable concrete.

\section{Acknowledgements}

This study was sponsored and supported by SLN, New Caledonia. The authors acknowledge the contribution and support of SLN through its research department. The 

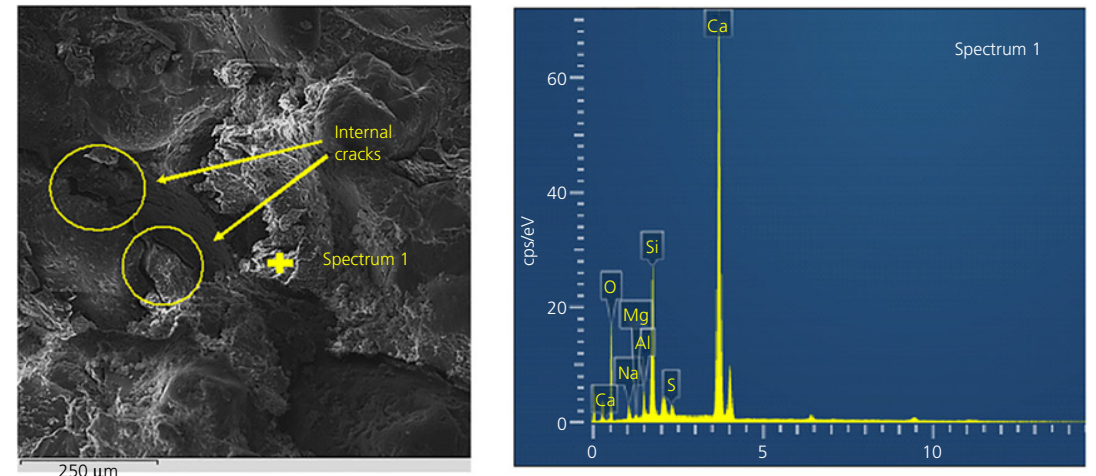

(a)
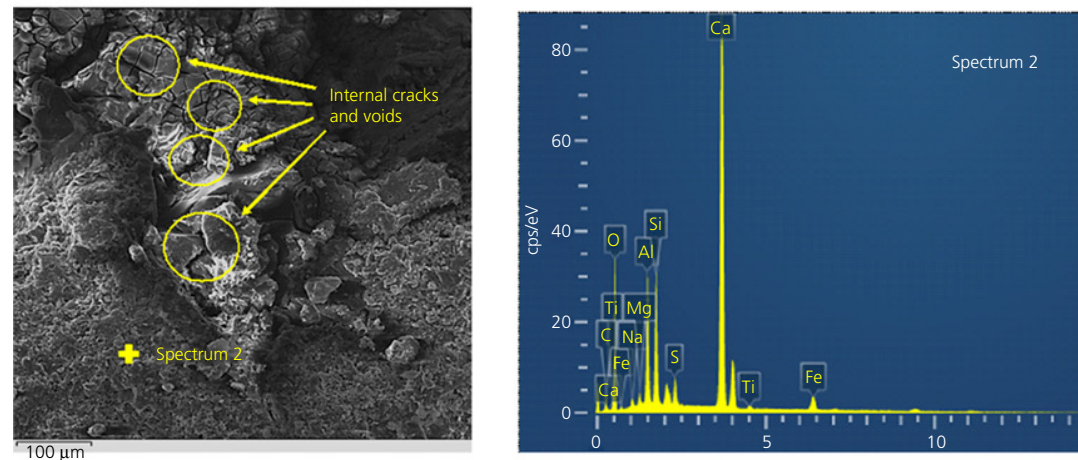

(b)
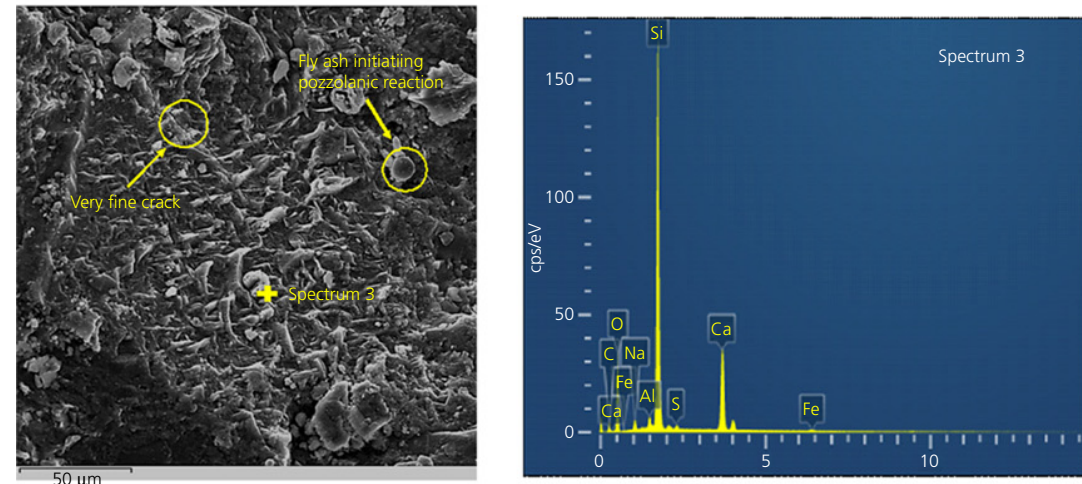

(c)
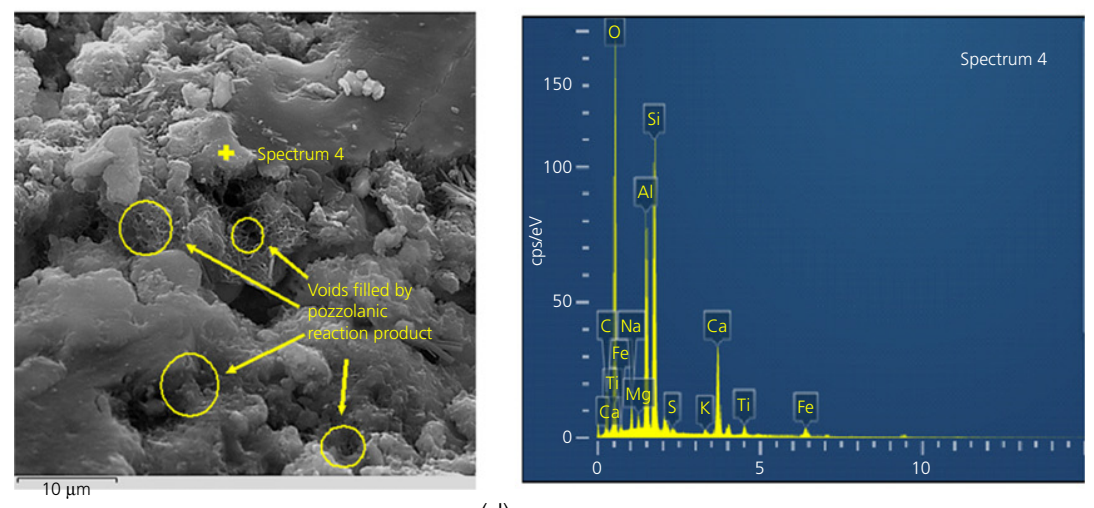

(d)

Figure 11. SEM and EDS data of the samples after wet-dry cycles: (a) PC-FNS0; (b) PC-FNS100; (c) FA-FNS0; (d) FA-FNS100 (cps/eV: counts per second) 
authors are also thankful to BGC Cemtech, Western Australia and Microscopy and Microanalysis Facility - John de Laeter Centre, Curtin University for their support to the work.

\section{REFERENCES}

Andrade LB, Rocha JC and Cheriaf M (2009) Influence of coal bottom ash as fine aggregate on fresh properties of concrete. Construction and Building Materials 23(2): 609-614.

ASTM (1997) C1202-97: Standard test method for electrical indication of concrete's ability to resist chloride ion penetration. ASTM International, West Conshohocken, PA, USA

ASTM (2004) ASTM C1585-04: Standard test method for measurement of rate of absorption of water by hydraulic-cement concretes. ASTM International, West Conshohocken, PA, USA.

ASTM (2006) ASTM C642-06: Standard test method for density, absorption, and voids in hardened concrete. ASTM International, West Conshohocken, PA, USA

Bijen J (1996) Benefits of slag and fly ash. Construction and Building Materials 10(5): 309-314.

CCAA (Cement Concrete \& Aggregates Australia) (2009) Report, June: Chloride Resistance of Concrete. CCAA, Mascot, NSW, Australia.

Choi YC and Choi S (2015) Alkali-silica reactivity of cementitious materials using ferro-nickel slag fine aggregates produced in different cooling conditions. Construction and Building Materials 99: 279-287, https://dx.doi.org/10.1016/j.conbuildmat. 2015.09.039.

Dragaš J, Ignjatović I, Tošić N and Marinković S (2016) Mechanical and time-dependent properties of high-volume fly ash concrete for structural use. Magazine of Concrete Research 68(12): 632-645, http://dx.doi.org/10.1680/jmacr.15.00384.

Ghafoori N and Bucholc J (1996) Investigation of lignite-based bottom ash for structural concrete. Journal of Materials in Civil Engineering 8(3): 128-137.

Kadam MP and Patil YD (2015) Effect of sieved coal bottom ash as a sand replacement on the properties of cement concrete. Magazine of Concrete Research 67(5): 227-234, http://dx.doi.org/10.1680/ macr.14.00179.

Katsiotis NS, Tsakiridis PE, Velissariou D et al. (2015) Utilization of ferronickel slag as additive in Portland cement: a hydration leaching study. Waste and Biomass Valorization 6(2): 177-189.

Kou SC and Poon CS (2009) Properties of concrete prepared with crushed fine stone, furnace bottom ash and fine recycled aggregate as fine aggregates. Construction and Building Materials 23(8) 2877-2886.

Kuroda M, Watanabe T and Terashi N (2000) Increase of bond strength at interfacial transition zone by the use of fly ash. Cement and Concrete Research 30(2): 253-258.

Manso JM, Polanco JA, Losanez M and González JJ (2006) Durability of concrete made with EAF slag as aggregate. Cement and Concrete Composites 28(6): 528-534.

Pellegrino C and Gaddo V (2009) Mechanical and durability characteristics of concrete containing EAF slag as aggregate. Cement and Concrete Composites 31(9): 663-671.

Rahman MA, Sarker PK, Shaikh FUA and Saha AK (2017) Soundness and compressive strength of Portland cement blended with ground granulated ferronickel slag. Construction and Building Materials 140: 194-202, https://dx.doi.org/10.1016/j.conbuildmat. 2017.02 .023$.

SA (Standards Australia) (1998) AS 2758.1-98: Aggregates and rock for engineering purposes - concrete aggregates. Standards Australia Limited, Sydney, NSW, Australia.

SA (2014) AS 1012.9-14: Aggregates and rock for engineering purposes - concrete aggregates. Standards Australia Limited, Sydney, NSW, Australia.
Saha AK and Sarker PK (2016) Expansion due to alkali-silica reaction of ferronickel slag fine aggregate in OPC and blended cement mortars. Construction and Building Materials 123: 135-142, https://dx.doi.org/10.1016/j.conbuildmat.2016.06.144.

Saha AK and Sarker PK (2017a) Sustainable use of ferronickel slag fine aggregate and fly ash in structural concrete: mechanical properties and leaching study. Journal of Cleaner Production 162: 438-448, https://dx.doi.org/10.1016/j.jclepro.2017.06.035.

Saha AK and Sarker PK (2017b) Compressive strength of mortar containing ferronickel slag as replacement of natural sand. Procedia Engineering 171: 689-694, https://dx.doi.org/10.1016/ j.proeng.2017.01.410.

Sakoi Y, Aba M, Tsukinaga $Y$ and Nagataki S (2013) Properties of concrete used in ferronickel slag aggregate. Proceedings of the $3 \mathrm{rd}$ International Conference on Sustainable Construction Materials and Technologies, Tokyo, Japan, pp. 1-6.

Sato T, Watanabe K, Ota A, Aba M and Sakoi Y (2011) Influence of excessive bleeding on frost susceptibility of concrete incorporating ferronickel slag as aggregates. In Proceedings of the 36th Conference on Our World in Concrete \& Structures, Singapore. Available online at: http://www.claisse.info/2013\%20papers/data/e337.pd.

Shehata MH, Thomas MD and Bleszynski RF (1999) The effects of fly ash composition on the chemistry of pore solution in hydrated cement pastes. Cement and Concrete Research 29(12): 1915-1920.

Shoya M, Sugita S, Tsukinaga Y, Aba M and Tokuhasi K (1999) Properties of self-compacting concrete with slag fine aggregates. In Exploiting Wastes in Concrete (Dhir RK and Jappy TG (eds)). Thomas Telford Publishing, London, UK, pp. 121-130.

Silva A, Neves R and de Brito J (2017) Statistical modelling of the influential factors on chloride penetration in concrete. Magazine of Concrete Research 69(5): 255-270, http://dx.doi.org/10.1680/jmacr. 16.00379 .

Soutsos M, Hatzitheodorou A, Kanavaris F and Kwasny J (2017) Effect of temperature on the strength development of mortar mixes with GGBS and fly ash. Magazine of Concrete Research 69(16): 787-801, http://dx.doi.org/10.1680/jmacr.16.00268.

Togawa K, Shoya M and Kokubu K (1996) Characteristics of bleeding, freeze-thaw resistance and watertightness of concrete with ferro-nickel slag fine aggregates. Journal of the Society of Materials Science, Japan 45(1): 101-109.

Tomosawa F, Nagataki S, Kajiwara T and Yokoyama M (1997) Alkali-aggregate reactivity of ferronickel-slag aggregate concrete. In Proceedings of 4th CANMETIACI International Conference on Durability of Concrete (Malhotra VM (ed.)). American Concrete Institute, Farmington Hills, MI, USA, ACI Special Publication 170, Vol. II, pp. 1591-1602.

Vicroads (Roads Corporation of Victoria) (2007) 89: Test Methods for the Assessment of Durability of Concrete. Roads Corporation of Victoria, Melbourne, Victoria, Australia.

Yüksel i, Bilir T and Özkan Ö (2007) Durability of concrete incorporating non-ground blast furnace slag and bottom ash as fine aggregate. Building and Environment 42(7): 2651-2659.

\section{How can you contribute?}

To discuss this paper, please submit up to 500 words to the editor at journals@ice.org.uk. Your contribution will be forwarded to the author(s) for a reply and, if considered appropriate by the editorial board, it will be published as a discussion in a future issue of the journal. 